\title{
Organic Vegetable Transplant Production
}

\author{
V.M. Russo ${ }^{1}$ \\ U.S. Department of Agriculture, Agricultural Research Service, South Central \\ Agricultural Research Laboratory, P.O.B. 159, Lane, OK 74555
}

Additional index words. Allium cepa, bell pepper, Capsicum annuum, Citrullus lanatus, conventional, onion, organic, transplant, watermelon, media

\begin{abstract}
The efficacy of using potting media and fertilizers that are alternatives to conventional materials to produce vegetable transplants needs clarification. Bell pepper, onion and watermelon seed were sown in Container Mix, Lawn and Garden Soil, and Potting Soil, which can be used for organic production in greenhouse transplant production. The alternative media were amended with a $1 \times$ rate of Sea Tea liquid fertilizer. Comparisons were made to a system using a conventional potting medium, Reddi-Earth, fertilized with a half-strength $(0.5 \times)$ rate of a soluble synthetic fertilizer (Peters). Watermelon, bell pepper and onion seedlings were lifted at 3,6 , and 8 weeks, respectively, and heights and dry weights determined. Watermelon were sufficiently vigorous for transplanting regardless of which medium and fertilizer was used. Bell pepper and onion at the scheduled lifting were sufficiently vigorous only if produced with conventional materials. Additional experiments were designed to determine the reason(s) for the weaker seedlings when the alternative products were used. Seedlings maintained in transplant trays, in which media amended weekly with Sea Tea were required to be held for up to an additional 34 days before being vigorous enough for transplanting. Six-week-old bell pepper, or 8-week-old onion, seedlings were transferred to Reddi-Earth in pots and supplied with Sea Tea or Peters fertilizer. Bell pepper treated with Peters were taller and heavier, but onions plants were similar in height and weight regardless of fertilizer used. Other pepper seed were planted in ReddiEarth and fertilized weekly with Sea Tea at $0.5 \times, 1 \times, 2 \times$, or $4 \times$ the recommended rate, or the $0.5 \times$ rate of Peters. There was a positive linear relationship between seedling height and dry weight for seedlings treated with increasing rates of Sea Tea. Other pepper seed were planted in to Potting Soil, or an organically certified potting medium (Sunshine), and fertilized with a $2 \times$ or $4 \times$ rate of Sea Tea or a $1 \times, 2 \times$, or $4 \times$ rate of an organic fertilizer (Rocket Fuel), or in Reddi-Earth fertilized with a $0.5 \times$ rate of Peters. There was a positive linear relationship between the rate of Rocket Fuel and heights and dry weights of bell pepper seedlings. However, even at the highest rate seedlings were not equivalent to those produced with conventional practices. Plants treated with the $4 \times$ rate of Sea Tea were similar to those produced using conventional materials. Use of Sunshine potting medium and the $4 \times$ rate of Sea Tea will produce bell pepper seedlings equivalent in height and dry weight to those produced using conventional materials. The $4 \times$ rate of Rocket Fuel used in Sunshine potting medium will produce adequate bell pepper seedlings. The original poor showing of seedlings in the alternative potting media appears to be due to fertilization with Sea Tea at a rate that does not adequately support seedling development.
\end{abstract}

Transplants are used to provide an early start for plants, produce seedlings of more consistent quality, and control spacing of plants in the field. Some vegetables traditionally started as transplants are bell pepper (Capsicum annuum L.) and tomato (Lycopersicon esculentum Mill.). Due to high cost of seed for some cultivars, transplants are being used to establish watermelon [Citrullus lanatus (Thunb.) Matsum. \& Nakai] in the field (Ko-

Received for publication 19 Oct. 2004. Accepted for publication 20 Nov. 2004. Mention of a trademark, vendor, or proprietary product does not constitute a guarantee or warranty of the product by the USDA and does not imply its approval to the exclusion of other products that may also be suitable. The article was prepared by USDA employees as part of their official duties. Copyright protection under US copyright law is not available for such works, and there is no copyright to transfer. The fact that the private publication in which the article appears is itself copyrighted does not affect the material that is a work product of the U.S. Government, which can be freely reproduced by the public.

${ }^{1}$ Research plant physiologist; e-mail vrussousda@lane-ag.org.
kalis-Burelle et al., 2003). Use of seedlings to establish onion (Allium cepa $\mathrm{L}$.) in the field has been studied (Herison et al., 1993; Kanton et al., 2002; Leskovar and Vavrina, 1999; Sargent et al., 2001; Russo, 2004).

Compost of various types have been used, generally successfully, for vegetable production (Ozores-Hampton et al., 1999; OzoresHampton and Peach, 2002; Raviv et al., 1998; Reis et al., 1998). Municipal waste has been tested for production of vegetable transplants, and it was found that heavy metal levels in the media and tissue were within acceptable limits (Falahi-Ardakani et al., 1987a, 1987b). However, other trials with sewer sludge indicate that heavy metals in phytotoxic concentrations were present in tomato and cabbage (Brassica oleracea L. Capitata group) seedlings (Sterrett et al., 1982).

Various recipes for potting mixes exist that do not contain synthetic components (Kuepper and Adam, 2003). Koller et al. (2004) used several plant based and animal based fertilizers in the production of vegetable transplants. They stipulated that plant based fertilizers should be mixed into the potting medium 2 weeks before sowing seed to prevent damage. Worm castings have been tested as a component of media for organic production of tomato and it was found seedling development improved as percent of worm castings in the medium increased (Ozores-Hampton and Vavrina, 2002). Regardless of their origin these materials and practices are generally referred to as being alternatives to conventional fertilzers, media and practices. To be accepted as commonplace in the industry alternative materials and practices must be compared to the existing conventional materials and practices. Additional information on how well vegetable transplants develop in alternative media need to be accumulated. Under the U.S. Department of Agriculture-Agricultural Marketing Service (USDA-AMS), National Organic Program (NOP) Final Rule (USDA-AMS, 2000) it is necessary if used in organic production that transplants be produced using organic materials and practices. This project was undertaken to examine the efficacy of organic materials and practices in the production of vegetable transplants, to compare organic media and practices to conventional media and practices, and if necessary develop additional experiments with new parameters to explore the reasons for benefits or shortcomings of the organic materials.

\section{Materials and Methods}

Initial experiment. The potting media were Container Mix, Lawn and Garden Soil, and Potting Soil, all from Garden-Ville (San Antonio, Texas), and Reddi-Earth Plug and Seedling Mix from Scotts-Sierra (Marysville, Ohio). The first three are described as natural by the manufacturer, do not contain synthetic components, and regardless of the implication of the names are suggested for use in all applicable practices in vegetable production. The Scotts-Sierra product is a commercially available conventional potting medium. Nutrient content and $\mathrm{pH}$ of the media are presented in Table 1. The first three media conform to being $100 \%$ organic as defined in the USDA-AMS-NOP. A process for certification of products to determine if they conform to the USDA-AMS-NOP standards exists through the Organic Materials Review Institute (OMRI), a nonprofit organization. However, if a product does not appear on that list it only means that it has not been sent to OMRI. for certification and may still conform to USDA-AMS-NOP standards.

The physical components listed on labels are Container Mix, pecan hulls, and other plant and mineral materials; Lawn and Garden Soil, pasteurized and composted top soil, orange sand, cedar flakes, and manure compost; Potting Soil, animal manures, stable bedding, composted vegetable and fruit residues, cedar flake, red sand, peat moss, vermiculite, Volcanite, and worm castings, and Reddi-Earth, horticultural vermiculite, and sphagnum peatmoss.

Each material was placed into 128 -cell transplant trays with cell volumes of $36 \mathrm{~cm}^{3}$ (Speedling, American Plant Products, Oklahoma City, Okla.). On 9 June 2003, seed of 'Walla Walla' onion were sown in four rows 


\begin{tabular}{|c|c|c|c|c|c|c|c|c|c|c|c|c|c|c|c|}
\hline \multirow[b]{3}{*}{ Source $^{y}$} & \multirow[b]{3}{*}{$\mathrm{pH}$} & \multicolumn{3}{|c|}{$\mathrm{N}$} & & & & & & & & & & & \multirow{3}{*}{$\begin{array}{c}\text { EC } \\
\left(\mu \mathrm{mho} \cdot \mathrm{cm}^{-1}\right)\end{array}$} \\
\hline & & \multirow{2}{*}{$\begin{array}{c}\text { Ammonium } \\
\left(\mu \mathrm{g} \cdot \mathrm{g}^{-1}\right)\end{array}$} & \multirow{2}{*}{$\begin{array}{l}\text { Nitrate } \\
\left(\mu g^{\prime} g^{-1}\right)\end{array}$} & \multirow{2}{*}{$\begin{array}{l}\text { Total } \\
(\%)^{x}\end{array}$} & \multicolumn{10}{|c|}{ Parameter $\left(\mu \mathrm{g} \cdot \mathrm{g}^{-1}\right)$} & \\
\hline & & & & & $\mathrm{P}$ & $\mathrm{K}$ & $\mathrm{B}$ & $\mathrm{Ca}$ & $\mathrm{Cu}$ & $\mathrm{Fe}$ & $\mathrm{Na}$ & $\mathrm{Mg}$ & $\mathrm{SO}_{4}$ & $\mathrm{Zn}$ & \\
\hline \multicolumn{16}{|l|}{ Medium } \\
\hline Container Mix & 6.6 & 8.9 & 132 & 0.80 & 4.6 & 303 & 0.5 & 923 & 13.4 & 28.3 & 119 & 169 & 2335 & 23.4 & 5300 \\
\hline Lawn and Garden Soil & 7.3 & 3.4 & 6 & 0.33 & 4.3 & 302 & 0.2 & 994 & 4.3 & 9.8 & 261 & 103 & 2141 & 8.4 & 5740 \\
\hline Potting Soil & 7.0 & 1.6 & 5 & 0.48 & 2.7 & 199 & 0.2 & 469 & 3.9 & 20.6 & 106 & 56 & 1253 & 8.0 & 2880 \\
\hline Sunshine ${ }^{w}$ & 6.1 & 69.7 & 85 & 0.99 & 8.4 & 22 & 0.1 & 100 & 1.0 & 14.5 & 29 & 59 & 90 & 1.2 & 1425 \\
\hline Reddi-Earth & 5.5 & 1.7 & $<1$ & 0.51 & 3.9 & 58 & 0.1 & 37 & 0.9 & 31.7 & 26 & 67 & 306 & 0.9 & 883 \\
\hline \multicolumn{16}{|l|}{ Fertilizer } \\
\hline Sea Teav & 3.1 & 42.6 & 25 & 0.035 & 1498.4 & 283 & 0.2 & 31 & 0.2 & 2.8 & 57 & 15 & 227 & 0.3 & 1958 \\
\hline Rocket Fuelv & 7.6 & 58.6 & 9 & 0.025 & 11.3 & 33 & 0.0 & 9 & 0.1 & 0.6 & 16 & 4 & 57 & 0.1 & 596 \\
\hline & & & & & & & & & $(\%)$ & & & & & & \\
\hline Peters $^{\mathrm{u}}$ & 5.9 & 9 & 1 & 10 & 10 & 10 & 0.01 & NL & 0.025 & 0.05 & NL & 0.25 & NL & 0.025 & NL \\
\hline
\end{tabular}

${ }^{\mathrm{z}}$ Analyses, with the exception of that for Peters, performed by the Oklahoma State University Soil, Water and Forage Analytical Laboratory, Stillwater, Okla.

${ }^{y}$ All media except Reddi-Earth meet N. O. P. standards to be labeled as $100 \%$ organic, arranged alphabetically.

${ }^{\mathrm{x}}$ To convert to $\mu \mathrm{g} \cdot \mathrm{g}^{-1}$ divide $\%$ by 10,000 .

"This material is discussed later in the paper, but included here for consistency of presentation; OMRI certified.

values are for $1 \times$ rates of Sea Tea and Rocket Fuel.

"Values for Peters at the 0.5 -fold rate are extrapolated from the Guaranteed Analysis on label which are presented for the $1.0 \times$ rate application; NL $=$ not listed.

perpendicular to the tray's long axis, two rows were skipped, seed of 'Royal Sweet' watermelon were sown in the next four rows, two rows were skipped, and seed of 'Bell Captain' bell pepper were sown in the last four rows. Untreated seed of cucumber and onion were available commercially. Generally speaking treated seed of this bell pepper cultivar is available commercially. However, an amount of untreated seed, sufficient to complete the experiments was obtained. There were three replicate trays for each medium. Trays were placed in a greenhouse and sufficient water provided from overhead sprinklers to maintain media in a moist condition. After plants in $80 \%$ of cells emerged they were thinned to one per cell. Total emergence was recorded at $14 \mathrm{~d}$ after planting. Bell pepper and watermelon were considered emerged when both cotyledons had expanded, and for onion when the cotyledon had broken the surface of the medium.

At $21 \mathrm{~d}$ after planting four seedlings/tray were lifted from centers of the two middle rows of those planted to watermelon. At lifting it was visually determined that plants in all media had sufficiently developed root systems and tops, 3 $\mathrm{cm}$ or taller, so that they could be transferred to the field using a mechanical transplanter. Plant heights were measured. Media were removed from roots by washing with tap water. Plants were placed in paper bags and then in to a forced air drying oven at $38^{\circ} \mathrm{C}$ until dry weights stabilized.

At thinning fertilization was begun for bell pepper and onion and continued weekly. Fertilizer was supplied at $600 \mathrm{~mL} /$ tray as a $1 \times$ rate $\left(7.5 \mathrm{~mL} \cdot \mathrm{L}^{-1}\right)$ solution of Sea Tea, 2.1N-3.3P-2.2K (Garden-Ville, San Antonio, Texas), to the alternative potting media, and as a $0.5 \times$ rate $\left(5 \mathrm{~g} \cdot \mathrm{L}^{-1}\right)$ solution of a water soluble synthetic fertilizer (Peters, 20N-20P-20K, Spectrum Group, St. Louis, Mo.), to trays containing Reddi-Earth. The Sea Tea label directs that the material not be applied to the plant until the fourth true leaf state. For continuity all fertilizer was directed, as much as possible, to the surface of the media.

At the initiation of the project the NOP rule concerning compost tea was not clear. It has since been determined that products contain- ing compost tea can be certified for use in an organic program if certain restrictions are met (USDA-AMS, 2004). The concern about compost tea is due primarily to the presence of Escherichia coli (Migula) Castellani and Chalmers, or enterococci bacteria that are human pathogens. Sea Tea contains compost tea. If a product containing compost tea has been pretested and meets EPA recommended quidelines (U.S. EPA, 2000) for recreational water quality for fecal contamination for Escherichia coli (126 CFU/100 mL ) or enterococci (33 CFU/100 mL), or if it has not been pre-tested for contamination, and not applied $>90 \mathrm{~d}$ before harvest, it can be used in production of food crops (USAD-AMS, 2004). The manufacturer of Sea Tea indicates that it conforms to the U.S. EPA guidelines (M. Beck, personal communication) and as a result it can be used in the unrestricted organic production of transplants for culture of pepper.

Nutrient content and $\mathrm{pH}$, for the $1 \times$ rate of Sea Tea and $0.5 \times$ rate of Peters differed (Table 1). At 6 weeks after emergence for pepper, and 8 weeks after emergence for onion, the same number of plants as for watermelon were removed from trays and the same types of data collected.

The experiment was arranged in a randomized complete block design with three replications (trays) and four observations (plants) per replication. Data were subjected to analysis of variance in the General Linear Models procedures, and means separated with the Ryan-Einot-Gabriel-Welsch posthoc test in SAS (SAS Inc., Cary, N.C.).

Adjustments initiated in response to results from the initial experiment. At 8 weeks for onion and 6 weeks for bell pepper plants produced using a conventional medium and practices were ready for establishment in the field. Seedlings in the organic media, based on threshold measurements of heights of leaves for onions $(12$ to $15 \mathrm{~cm})$, or heights $(10 \mathrm{~cm})$ and presence of expanded second true leaves for bell pepper, were determined to not meet the requirements to be transferred to the field using a mechanical transplanter. Additional experiments with various protocols were conducted to determine if a cause for the substandard development could be identified.

Extended maintenance of seedlings in the organic media, or transfer to a conventional medium. This part of the project was undertaken to determine if extended maintenance in transplant trays affected seedling development.

Plants remaining in transplant trays with the organic media were fertilized weekly with a $1 \times$ rate of Sea Tea. Additionally, from the remaining plants in trays three bell pepper and onion seedlings, containing the intact root ball and medium for the Container Mix, Lawn and Garden Soil, and Potting Soil media, were carefully removed from each tray and transferred to 1.5 -L volume pots containing Reddi-Earth. This is not a standard procedure for seedling production. It was undertaken to determine if the potting media contributed to the production of substandard seedlings. Plants transferred to pots were fertilized weekly with $50 \mathrm{~mL} /$ pot of a $0.5 \times$ rate solution of Peters water soluble synthetic fertilizer, or a like number of plants transferred to pots containing Reddi-Earth were fertilized weekly with $50 \mathrm{~mL} /$ pot of a $1 \times$ rate solution of Sea Tea.

The experiment was ended when a determination, based on the same criteria described previously, indicated that plants remaining in trays were, or were not, of sufficient vigor, or that it would be an extended time before seedlings would be vigorous enough, to be moved to the field using a mechanical transplanter. When those determinations were made three plants were removed from trays, or from the pots, and heights and dry weights determined as before. A completely randomized design was used. Data were subjected to the General Linear Models procedures in SAS, and means separated with the Ryan-Einot-Gabriel-Welsch posthoc test.

Establishment of transplants in a conventional medium and fertilization with organic and synthetic fertilizers. This part of the project was undertaken to determine the application rate of an organic fertilizer that would produce adequate sized transplants. The same type of trays were filled with Reddi-Earth. The conventional medium was used to remove any detrimental effects that might be associated with the organic media. Seed of the same bell pepper 
cultivar were sown in cells on 23 July 2003. At 2 weeks after emergence plants were thinned to one/cell. At that time weekly fertilization using $600 \mathrm{~mL} /$ tray of a $0.5 \times$ rate solution of Peters soluble synthetic fertilizer, or a $0.5 \times$, or $1 \times$, $2 \times$, or $4 \times$ rate solution of Sea Tea was begun. There were three trays for each fertilizer treatment. After 6 weeks, plants were removed from the center two rows of each tray. Plant heights and dry weights were determined as before. The experimental design was a randomized complete block with three replications and 12 observations/replication. Data were analyzed with linear regression and Pearson product moment correlation analyses in SAS.

Table 2. Dates seed sown, and dates of scheduled lifting and lifting after an extended period for seedlings of watermelon, bell pepper, and onion in the various media. Crops are presented in terms of ascending time to scheduled lifting.

\begin{tabular}{lcccc}
\hline \multirow{2}{*}{ Crop } & Date sown & & \multicolumn{2}{c}{ Date lifted } \\
\cline { 4 - 5 } in trays & Medium & Scheduled & Actual $^{2}$ \\
\hline Watermelon & 9 June & Reddi-Earth & 30 June & 30 June \\
& & Container Mix & 30 June & 30 June \\
& & Lawn and Garden Mix & 30 June & 30 June \\
Bell pepper & & Potting Soil & 30 June & 30 June \\
& 9 June & Reddi-Earth & 25 July & 25 July \\
& & Container Mix & 25 July & 18 Aug. \\
& & Lawn and Garden Mix & 25 July & 28 Aug. \\
Onion & Potting Soil & 25 July & 20 Aug. \\
& 9 June & Reddi-Earth & 8 Aug. & 8 Aug. \\
& & Container Mix & 8 Aug. & 8 Sept. \\
& & 8 Aug. & 11 Sept. \\
& & Lawn and Garden Mix & 8 Aug. & 2 Sept. \\
\hline
\end{tabular}

${ }^{2}$ Extended maintenance in flats was required for: bell pepper in Container Mix, Potting Soil, and Lawn and Garden Soil for an additional 24, 26, and 34 d, respectively, and onion in Potting Soil, Container Mix, Lawn and Garden Soil, and for an additional 24, 30, and 33 d, respectively. During this period plants were provided weekly fertilization with a $1 \times$ rate solution of Sea Tea.

Table 3. Heights and whole plant dry weights of greenhouse grown vegetable seedlings in transplant trays in organic and conventional media at scheduled lifting. ${ }^{2}$

\begin{tabular}{|c|c|c|c|c|c|c|}
\hline \multirow[b]{2}{*}{ Medium } & \multicolumn{2}{|c|}{ Bell pepper } & \multicolumn{2}{|c|}{ Onion } & \multicolumn{2}{|c|}{ Watermelon } \\
\hline & $\begin{array}{l}\mathrm{Ht} \\
(\mathrm{mm})\end{array}$ & $\begin{array}{c}\text { Dry } \\
\text { wt }(\mathrm{g})\end{array}$ & $\begin{array}{c}\mathrm{Ht} \\
(\mathrm{mm})\end{array}$ & $\begin{array}{c}\text { Dry } \\
\text { wt (g) }\end{array}$ & $\begin{array}{l}\text { Height } \\
(\mathrm{mm})\end{array}$ & $\begin{array}{c}\text { Dry } \\
\text { wt (g) }\end{array}$ \\
\hline$\overline{\text { Reddi-Earth }^{y}}$ & $111.2 \mathrm{a}^{\mathrm{x}}$ & $0.37 \mathrm{a}$ & $198.2 \mathrm{a}$ & $0.48 \mathrm{a}$ & $48.3 \mathrm{a}$ & $0.16 \mathrm{a}$ \\
\hline Container Mix & $41.3 \mathrm{~b}$ & $0.09 \mathrm{~b}$ & $105.3 b$ & $0.21 \mathrm{~b}$ & $43.8 \mathrm{a}$ & $0.09 b$ \\
\hline Potting Soil & $39.9 \mathrm{~b}$ & $0.06 \mathrm{~b}$ & $93.6 \mathrm{bc}$ & $0.19 \mathrm{~b}$ & $48.9 \mathrm{a}$ & $0.09 b$ \\
\hline Lawn and Garden Soil & $27.5 \mathrm{c}$ & $0.04 \mathrm{~b}$ & $82.2 \mathrm{c}$ & $0.11 \mathrm{~b}$ & $34.6 b$ & $0.10 \mathrm{~b}$ \\
\hline
\end{tabular}

${ }^{2}$ Scheduled lifting was 3 weeks after sowing for watermelon and 6 and 8 weeks after emergence for bell pepper, and onion, respectively.

${ }^{y}$ Reddi-Earth is a conventional medium and the others meet NOP standards as being $100 \%$ organic.

'Values in a column followed by the same letter are not significantly different, Ryan-Einot-Gabriel-Welsch posthoc test, $P<0.05$. media were begun using $600 \mathrm{~mL} /$ tray of a $1 \times$, or $2 \times$, or $4 \times$ rate of Rocket Fuel $(2 \mathrm{~N}-6 \mathrm{P}-1 \mathrm{~K}$; Garden-Ville), a nutrient source that can appropriately be termed $100 \%$ organic under NOP, in water, or with a $2 \times$ or $4 \times$ rate of Sea Tea, in water, and in Reddi-Earth with a $0.5 \times$ rate solution of Peters soluble synthetic fertilizer. A $1 \times$ rate of Rocket Fuel is $7 \mathrm{~g} \cdot \mathrm{L}^{-1}$. Nutrient content and $\mathrm{pH}$ for $1 \times$ rates of each fertilizer are presented in Table 1. Concentrations were not standardized since the aim was to determine the rate of each fertilizer that best supported seedling development. Plants were exposed to no more than $14 \mathrm{~h}$ of light, with daylight being extended by exposure to light provided by fluorescent bulbs (Son Agro, 430 lumens $/ \mathrm{m}^{2}$; Phillips, Sommerset, N.J.).

At 6 weeks after emergence 12 plants were removed from the center two rows of each tray. Plant heights and dry weights were determined as before. The experimental design was a randomized complete block with three replications for combinations of medium and fertilizer with 12 observations/replication. Data were subjected to analysis of variance in the General Linear Models procedures in SAS. Means were separated with the Ryan-EinotGabriel-Welsch posthoc test.

\section{Results}

pHand nutrient content of media and fertilizers. The $\mathrm{pH}$ values were 5.5, 6.1, 6.6, 7.0, and 7.3 for Reddi Earth, Sunshine, Container Mix, Potting Soil, and Lawn and Garden Soil, respectively. The initial nutrient contents of the potting media appeared to differ. The Container Mix appeared to have concentrations of most nutrients that were greater than, or equal to, concentrations of these same nutrients in other media. Electrical conductivity (EC) values appeared to differ between the organic media with Lawn and Garden Soil seeming to have the highest value, and all organic media had EC values that appeared to be $1.6 \times$ to $6.5 \times$ higher than the conventional medium. Sea Tea appeared to have $3.2 \times$ the EC value than did the Rocket Fuel.

There were differences in $\mathrm{pH}$ of fertilizers with values of $3.1,5.9$, and 7.6 for Sea Tea, Peters, and Rocket Fuel, respectively. The 1×

Table 4. Heights and dry weights of bell pepper and onion plants maintained for an extended period ${ }^{\mathrm{z}}$ in transplant trays in organic media where fertilization was with Sea Tea ${ }^{y}$ or after transplanting in to Reddi-Earth in pots where fertilization was with Sea Tea or Peters ${ }^{y}$ soluble fertilizer.

\begin{tabular}{|c|c|c|c|c|c|c|}
\hline Condition of growth & \multicolumn{6}{|c|}{ Medium in which plants were maintained or transferred from } \\
\hline Maintained in transplant tray & $65.3 \mathrm{c}^{\mathrm{x}}$ & $0.22 \mathrm{c}$ & $79.9 \mathrm{c}$ & $0.28 \mathrm{c}$ & $51.2 \mathrm{c}$ & $0.14 \mathrm{c}$ \\
\hline Transferred to Reddi-Earth fertilized with Sea Tea & $118.7 \mathrm{~b}$ & $1.45 \mathrm{~b}$ & $136.0 \mathrm{~b}$ & $1.91 \mathrm{~b}$ & $142.7 \mathrm{~b}$ & $2.47 \mathrm{~b}$ \\
\hline Transferred to Reddi-Earth fertilized with Peters & $192.7 \mathrm{a}$ & $3.37 \mathrm{a}$ & $178.7 \mathrm{a}$ & $2.76 \mathrm{a}$ & $186.0 \mathrm{a}$ & $3.58 \mathrm{a}$ \\
\hline \multicolumn{7}{|l|}{ Onion } \\
\hline Transferred to Reddi-Earth fertilized with Peters & 246.7 a & $0.62 \mathrm{a}$ & $251.0 \mathrm{a}$ & $0.31 \mathrm{a}$ & $344.0 \mathrm{a}$ & $0.54 \mathrm{~b}$ \\
\hline
\end{tabular}

${ }^{2}$ Extended maintenance in flats was required for bell pepper in Container Mix, Potting Soil, and Lawn and Garden Soil for an additional 24, 26, and 34 d, respectively, and onion in Potting Soil, Container Mix, and Lawn and Garden Soil for an additional 24, 30, and 34 d, respectively. Plants transferred to pots and fertilized with Sea Tea and Peters were maintained for the same length of time as plants in flats. Comparisons were by growth conditions since the length of the extended maintenance period varied after transfer to the Reddi-Earth.

${ }^{y}$ Sea Tea was applied at a $1 \times$ rate $\left(7.5 \mathrm{~mL} \cdot \mathrm{L}^{-1}\right)$ and Peters was applied at a $0.5 \times$ rate $\left(5 \mathrm{~g} \cdot \mathrm{L}^{-1}\right)$.

${ }^{x}$ Values in a column followed by the same letter are not significantly different, Ryan-Einot-Gabriel-Welsch posthoc test, $P<0.05$. 

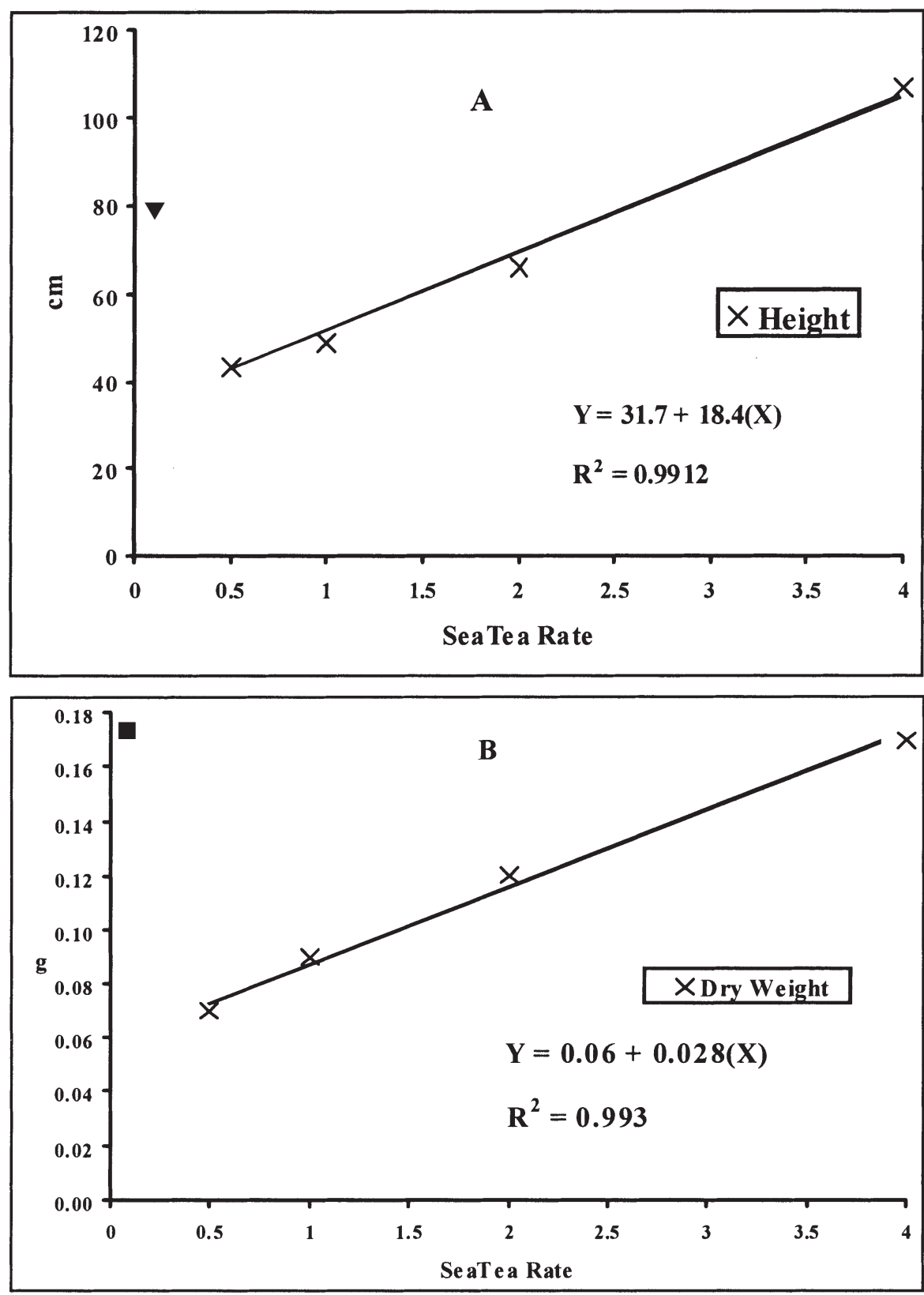

Fig. 1. Linear regression analysis of effects of rates of Sea Tea applied to Reddi-Earth medium on (A) transplan height, and (B) whole transplant dry weight at lifting. In the graphs the single data points in A indicated by $\boldsymbol{\nabla}$, and B indicated by $\boldsymbol{\square}$, represent the values recorded for the control plants maintained in Reddi-Earth fertilized with the Peters soluble synthetic fertilizer. The $1 \times$ rate of Sea Tea is $7.5 \mathrm{~mL} \cdot \mathrm{L}^{-1}$.

Table 5. Correlations between rate of Sea Tea and heights and dry weights of bell pepper plants maintained in the conventional medium ReddiEarth in transplant trays for 6 weeks and fertilized with various rates of Sea Tea.

\begin{tabular}{|c|c|c|}
\hline \multirow[b]{2}{*}{ Source } & \multicolumn{2}{|c|}{$\begin{array}{c}\text { Pearson correlation } \\
\text { coefficients }(\mathrm{N}=4) \\
P>|r| \text { under Ho: Rho }=0 \\
\text { Transplant }\end{array}$} \\
\hline & $\mathrm{Ht}(\mathrm{mm})$ & Dry wt $(\mathrm{g})$ \\
\hline \multirow[t]{2}{*}{ Sea Tea rate } & 0.9956 & 0.9965 \\
\hline & 0.0044 & 0.0035 \\
\hline \multirow[t]{2}{*}{ Transplant height } & & 0.9842 \\
\hline & & 0.0158 \\
\hline
\end{tabular}

rate of the organic fertilizers had N-P-K levels that appeared to be very low when compared to Peters. Levels of many micronutrients in Peters appeared to be below those of the
Table 6. Effect of medium and fertilizer rate on maintained in transplant trays for 6 weeks following emergence.

\begin{tabular}{lcc}
\hline Source & $\mathrm{Ht}(\mathrm{mm})$ & Dry wt $(\mathrm{g})$ \\
\hline Medium $(\mathrm{M})^{\mathrm{z}}$ & $*$ & $*$ \\
Fertilizer $(\mathrm{F})^{\mathrm{z}}$ & $* *$ & $*$ \\
$\begin{array}{l}\text { Interaction } \\
\mathrm{M} \times \mathrm{F}\end{array}$ & $*$ & $*$ \\
\hline
\end{tabular}

${ }^{2}$ The media were Potting Soil, Sunshine, or ReddiEarth and the fertilizers were Rocket Fuel, Sea Tea or Peters.

**** Significant at $P<0.5$ or 0.01 , respectively, ANOVA.

alternative fertilizers, and there appeared to be differences in content of micronutrients between the organic fertilizers.

Initial experiment. Media type did not heights and dry weights of bell pepper plants affect total emergence which averaged above 95\% across all media. Dates of scheduled lifting, and dates of lifting after extended maintenance, for the various crops differed (Table 2). Watermelon plants treated with organic or conventional materials were ready at the scheduled lifting. Bell pepper and onion plants treated with conventional materials were ready at scheduled lifting. An additional 24 , 26 , and $34 \mathrm{~d}$ were required for bell pepper to be maintained in transplant trays containing Container Mix, Potting Soil, and Lawn and Garden Soil, respectively, before seedlings were vigorous enough for establishment in the field with a mechanical transplanter. An additional 24, 30, and $33 \mathrm{~d}$ was required for onion to be maintained in the transplant trays containing Potting Soil, Container Mix and Lawn and Garden Soil, respectively, before seedlings were vigorous enough, or would not attain the necessary vigor, for establishment in the field with a mechanical transplanter.

Tallest and heaviest bell pepper and onion seedlings at the scheduled lifting were those in Reddi-Earth (Table 3). Heights of watermelon were similar across treatments, except for those in Lawn and Garden Soil which were smaller, and dry weights of watermelon were heaviest for plants in Reddi-Earth. It was unclear from the results whether the media or the Sea Tea was the cause of the development of substandard transplants. Additional experiments were designed to attempt to clarify the reasons for the production of substandard seedlings in some of the cases.

Adjustments initiated in response to results from the initial experiment: Extended maintenance of seedlings in the organic media or transfer to a conventional medium. Extended maintenance in trays, or transfer to pots, affected plant heights and weights (Table 4). For bell pepper and onion results were compared within a medium, but not across media, since time of extended maintenance differed. For bell pepper, plants transferred to pots containing Reddi-Earth and fertilized with Peters, were taller and heavier than those transferred to pots containing Reddi-Earth and fertilized with Sea Tea. In all cases plants transferred to pots were taller and heavier than plants maintained in transplant trays and fertilized with Sea Tea. For onion, plants transferred to pots, and fertilized with Peters, were similar in height and dry weight to those transferred to pots and fertilized with Sea Tea. The exception was for dry weights of plants originally in Lawn and Garden Soil transferred to pots and fertilized with Peters. These plants had lower dry weights than those transferred to pots and fertilized with Sea Tea. In all cases plants transferred to pots were taller and heavier than those maintained in transplant trays and fertilized with Sea Tea. It was concluded that there was some component of Sea Tea responsible for substandard seedling development. It was also concluded that what ever the factor was could be overcome by use of the conventional medium.

Establishment of transplants in a conventional medium and fertilization with organic and synthetic fertilizers. Height and dry weights of transplants increased as Sea Tea 

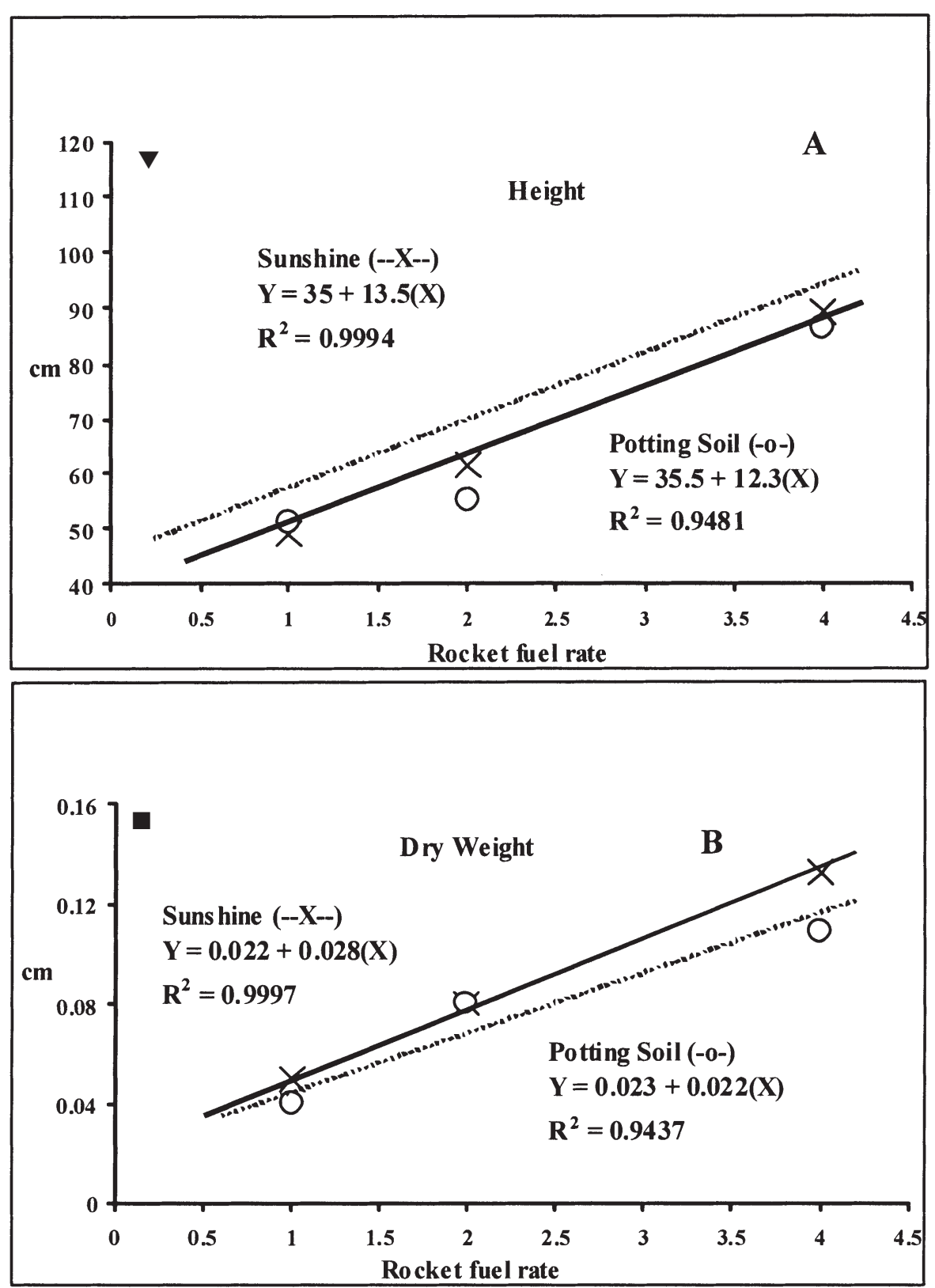

Fig. 2. Linear regression analysis of effects of rates of Rocket Fuel applied to the organic potting media, Potting Soil or Sunshine, on (A) transplant height and (B) whole transplant dry weight at lifting. In graphs the single data points in A indicated by $\boldsymbol{\nabla}$, and B indicated by $\boldsymbol{\square}$, represent the values recorded for the control plants maintained in Reddi-Earth and fertilized with the Peters soluble synthetic fertilizer. The $1 \times$ rate of Rocket Fuel is $7 \mathrm{~g} \cdot \mathrm{L}^{-1}$

Table 7. Correlations between rate of Rocket Fuel and heights and dry weights of bell pepper plants maintained in the Potting Soil and Sunshine media in transplant trays for 6 weeks and fertilized with various rates of Rocket Fuel.

\begin{tabular}{|c|c|c|c|c|}
\hline \multirow[b]{4}{*}{ Source } & \multicolumn{4}{|c|}{$\begin{array}{l}\text { Pearson correlation coefficients }(\mathrm{N}=3) \\
\qquad P>|r| \text { under Ho: Rho }=0 \\
\text { Medium }\end{array}$} \\
\hline & \multicolumn{2}{|c|}{ Potting Soil } & \multicolumn{2}{|c|}{ Sunshine } \\
\hline & \multicolumn{2}{|c|}{ Transplant } & \multicolumn{2}{|c|}{ Transplant } \\
\hline & $\mathrm{Ht}(\mathrm{mm})$ & Dry wt (g) & $\mathrm{Ht}(\mathrm{mm})$ & $\overline{\text { Dry wt }(\mathrm{g})}$ \\
\hline \multirow[t]{2}{*}{ Rocket Fuel rate } & 0.817 & 0.2878 & 0.865 & 0.7392 \\
\hline & 0.0001 & 0.0025 & 0.0001 & 0.0001 \\
\hline \multirow[t]{2}{*}{ Transplant height } & & 0.1281 & & 0.6777 \\
\hline & & 0.1865 & & 0.0001 \\
\hline
\end{tabular}

rate increased (Fig. 1). Heights of control plants (conventional medium and fertilizer) were between those for plants fertilized with Sea Tea at the $2 \times$ and $4 \times$ rates. Control dry weights were similar to plants fertilized with the $4 \times$ rate of Sea Tea. Significant positive correlations existed between plant height and dry weight and Sea Tea rate, and over all rates plant height was positively correlated with plant dry weight (Table 5). Sea Tea does not appear to be toxic to developing bell pepper transplants even though it was applied before the recommended four true leaf stage as stated on the label.Also, it appears the recommended rate $(1 \times)$ is insufficient for optimal plant development. Plants treated with a $3 \times$ Sea Tea rate produced plants similar in height to controls. Plants treated with 4-fold Sea Tea were taller than controls, but had similar dry weights. This suggests that Sea Tea provides sufficient nutrition at the higher rates to support seedling development.

Transplant development in organic systems and comparison to the conventional system. Medium type and rate of fertilizer, and their interaction, affected seedling heights and dry weights (Table 6). Since there are three points, the data for plants receiving Rocket Fuel are presented in terms of how the data fit a linear relationship. The data from the previous section indicated that there is a linear relationship for seedling height and dry weight in response to Sea Tea rate. There were only two data points for the seedlings receiving Sea Tea in this section since the aim was to differentiate between the best Sea Tea rates. It is possible to fit a line with two points, but it is less precise than if more data points are used. As a result the data involving Sea Tea are compared in tabular form.

It was determined that transplant height and dry weight increased in a linear fashion as Rocket Fuel rate increased regardless of which organic medium was used (Fig. 2). However, even at the highest Rocket Fuel rate, seedling heights and dry weights did not appear to be equal to those for seedlings produced in ReddiEarth and fertilized with Peters. Transplant heights and dry weights were correlated with Rocket Fuel rate regardless of the organic potting medium used (Table 7). When produced in Potting Soil, transplant heights were not correlated with transplant dry weights. When produced in Sunshine medium, transplant heights were correlated with transplant dry weights. The reason for this is not apparent, but likely has to do with some component of the medium that was not tested.

When Sea Tea was applied to the Potting Soil it was determined that the $4 \times$ rate produced seedlings that were taller and heavier than those produced in the Reddi-Earth and fertilized with Peters (Table 8). The conventionally produced seedlings were generally taller and heavier than those provided the $2 \times$ rate of Sea Tea. The exception was for dry weights of seedlings produced in Sunshine and fertilized with Peters, or with Sea Tea at the $2 \times$ rate, where dry weights were similar.

\section{Discussion}

Watermelon transplant development does not seem to be greatly affected by the medium in which the seedlings were produced. This is likely due to the short time that watermelon transplants are kept in trays before being transferred to the field. The levels of nutrients in the media, in conjunction with those stored in 
Table 8. Heights and dry weights of bell pepper in transplant trays maintained under conventional management (conventional potting medium Reddi-Earth and fertilized with Peters), or in trays containing the Potting Soil or Sunshine potting media and fertilized with two levels of Sea Tea.

\begin{tabular}{|c|c|c|c|c|}
\hline \multirow[b]{2}{*}{ Fertilizer } & \multicolumn{2}{|c|}{ Potting Soil } & \multicolumn{2}{|c|}{ Sunshine } \\
\hline & $\mathrm{Ht}(\mathrm{mm})$ & $\begin{array}{c}\text { Dry } \\
\text { wt (g) }\end{array}$ & Ht (mm) & $\begin{array}{c}\text { Dry } \\
\text { wt (g) }\end{array}$ \\
\hline Sea Tea 4-fold & 122.5 & 0.194 & 139.3 & 0.227 \\
\hline Control $^{z}$ & $114.9^{* *}$ & $0.159^{* *}$ & $114.9^{* * *}$ & $0.159^{* *}$ \\
\hline Sea Tea 2-fold & $84.9^{* *}$ & $0.113^{* *}$ & $103.3^{*}$ & $0.134^{\mathrm{NS}}$ \\
\hline
\end{tabular}

${ }^{\mathrm{z}}$ Control was Peters applied at the $0.5 \times$ rate of $5 \mathrm{~g} \cdot \mathrm{L}^{-1}$. Rates of Sea Tea applied at the $2 \times$ and $4 \times$ rates which were 15 and $30 \mathrm{~mL} \cdot \mathrm{L}^{-1}$, respectively.

NS,*,*** Nonsignificant or significantly different at $P<0.01$ or 0.05 , least squares means analysis. In this type of analysis a number in a column is compared to the number immediately below it.

the cotyledons, are likely sufficient to produce watermelon transplants of the necessary size. For bell pepper and onion, which are typically kept in transplant trays for longer periods, conditions of growth during the initial experiment resulted in production of substandard transplants. Medium salinity levels, measured as EC, can affect plant development. EC levels of at least $2000 \mu \mathrm{mho} \cdot \mathrm{cm}^{-1}$ are considered to cause yield losses (Lorenz and Maynard, 1988). EC values of all the organic media, except for Sunshine, were above this level. It may be that these EC values contributed to the substandard development of bell pepper and onion in the initial experiments. However, for 6-week-old lettuce (Lactuca sativa L.) and chinese cabbage (B. rapa var pekinensis L.) transplants, fresh weights did not appear to be affected when high EC values infrequently occurred in media fertilized with materials produced from lupin or malt sprouts (Koeller et al., 2004). Sea Tea and Rocket Fuel EC levels were in a range at the $1 \times$ rate that, taken alone, might only have caused negligible effects on yield. However, this type of interpretation of effects of salinity on transplant development needs further study since yield occurs at a time and place separate from when and where transplants are produced. Salt levels in media need to be monitored over time to determine if they are correlated with transplant development. The $\mathrm{pH}$ values of the media are in a range that could support production of most vegetable seedlings (Lorenz and Maynard, 1988). Medium acidity does not appear to be a main reason for substandard production of seedlings. There were more differences than similarities in concentrations of nutrients between media. Initial nutrient content in the organic potting media did not appear to affect seedling development since those produced in Container Mix, which appeared to have higher levels of most nutrients, were generally no better than in the other organic media.

The data indicate that production of substandard seedlings was not due to toxicity of Sea Tea fertilizer. At least for bell pepper it appears that the label directions for use of Sea Tea underestimate the amount required to produce seedlings equal to those produced with the conventional potting medium and soluble fertilizer control. The concept of nonconventional production relies on changing the nature of the soil. Nonconventional fertilizers are generally lower in $\mathrm{N}-\mathrm{P}-\mathrm{K}$ than synthetic fertilizers and they release the nutrients over a longer time period. There is only a short time period available to produce seedlings for transplants, and no time to build the soil in the cells of transplant flats.

For bell pepper it appears that the acidic nature of Sea Tea used with the Sunshine medium, maybe overcome due to availability of more nutrients at the $4 \times$ application rate. Sea Tea is suitable for production of bell pepper seedlings for transplants in an organic system. It may advisable that the last application in the greenhouse be $>90 \mathrm{~d}$ from harvest until more information becomes available on presence of bacterial populations in Sea Tea or other compost teas. The data indicate that a $3 \times$ rate of Sea Tea could likely be used to produce transplants similar to those produced using conventional management techniques. It may be necessary to test this combination of medium and fertilizer for applicability in the production of transplants of other crops.

The application of Rocket Fuel in a solution for use in production of seedlings was less effective. Rocket Fuel is not completely soluble, and the distribution of nutrients may not be uniform, or available to plants, due to settling in the application container, or after delivery to the potting medium. It may be that a higher application rate of Rocket Fuel, than that used in these experiments, would allow for production of seedlings in a completely organic program that are equal to those produced with conventional methods. However, even with the probable limitations of the solubility of the material the seedlings were, based on the results, adequate for establishment in the field with a mechanical transplanter. It remains to be determined if transplants produced with organic systems will develop in to plants that will produce in the field at levels comparable to those under conventional culture.

\section{Literature Cited}

Falahi-Ardakani, A., J.C. Bouwkamp, F.R. Gouin, and R.L. Chaney. 1987a. Growth response and mineral uptake of vegetable transplants in a composted sewage sludge amended medium. I. Nutrient supplying power of the medium. J. Environ. Hort. 5:107-111.

Falahi-Ardakani, A., F.R. Gouin, J.C. Bouwkamp, and R.L. Chaney. 1987b. Growth response and mineral uptake of vegetable transplants in a composted sewage sludge amended medium. II. Influenced by time of application of $\mathrm{N}$ and K. J. Environ. Hort. 5:112-115.

Herison, C., J.G. Masabni, and B.H. Zandstra. 1993. Increasing seeding density, age, and nitrogen fertilization increases onion yield. HortScience 28:23-25.
Kanton, R.A.L., L. Abbey, R.G. Hilla, M.A. Tabil, and N.D. Jan. 2002. Influence of transplanting age on bulb yield and yield components of onion (Allium cepa L.). J. Veg. Crop Prod. 8(2):27-37.

Kokalis-Burelle, N., C. Vavrina, M.S. Reddy, and J.W. Kloepper. 2003. Amendment of muskmelon and watermelon transplant media with plant growth-promoting rhizobacteria: Effects on seedling quality, disease, and nematode resistance. HortTechnology 13:476-482.

Koller, M., T. Alfoldt, M. Siegrist, and F. Werbel. 2004. A comparison of plant and animal based fertiliser for the production of organic vegetable transplants. Acta Hort. 631:209-215.

Kuepper, G. and K. Adam. 2003. Organic potting mixes for certified production. Horticulture technical note. Appropriate technology transfer for rural areas. http://attra.ncat.org/attra-pub/ potmix.html.

Leskovar, D.I. and C.S. Vavrina. 1999. Onion growth and yield are influenced by transplant traycell size and age. Scientia Hort. 80:133-143.

Lorenz, O.A. and D.N. Maynard. 1988. Knott's handbook for vegetable growers. Wiley-Interscience, New York.

Ozores-Hampton, M. and D.R.A. Peach. 2002. Biosolids in vegetable production systems. HortTechnology 12:336-340.

Ozores-Hampton, M.P. and C.S. Vavrina. 2002. Worm castings: an alternative to sphagnum peat moss in organic tomato (Lycopersicon esculentum Mill.) transplant production. Proceedings of the international composting and compost utilization. Columbus, Ohio, 6-8 June.

Ozores-Hampton, M.P., C.S. Vavrina, and T.A. Obreza. 1999. Yard trimmings-biosolids compost: possible alternative to sphagnum peat moss in tomato (Lycopersicon esculentum Mill.) transplant production. Compost Sci. Utiliz. $7(4): 42-49$.

Raviv, M., B.Z.Zaidman, and Y. Kapulnik. 1998. The use of compost as a peat substitute for organic vegetable transplants production. Compost Sci. Utiliz. 6:46-52.

Reis, M., F.X. Martinez, M. Soliva, and A.A. Monteiro. 1998. Composted organic residues as a substrate component for tomato transplant production. Acta Hort. 469:263-273.

Russo, V.M. 2004. Greenhouse grown transplants as an alternative to bare-root transplants for onions. HortScience 39:1267-1271.

Sargent, S.A., P.J. Stoffella, and D.N. Maynard. 2001. Harvest date affects yield and postharvest quality of nondried, short-day onions. HortScience 36:112-115.

Sterrett, S.B., R.L. Chaney, C.W. Reynolds, F.D. Schales, and L.W. Douglass. 1982. Transplant quality and metal concentrations in vegetable transplants grown in media containing sewage sludge compost. HortScience 17:920-922.

U.S. Department of Agriculture, Agricultural Marketing Service. 2000. National organic program; final rule. 7 CFR Part 205. Fed. Reg. 21 Dec. 2000.

U.S. Department of Agriculture, Agricultural Marketing Service. 2004. National organic standards board. Compost tea task force final report. www. ams.usda.gov/nosb/meetings/CompostTeaTaskForceFinalReport.pdf.

United States Environmental Protection Agency. 2000. Improved enumeration methods for the recreational water quality indicators: Enterococci and Escherichia coli.U.S. EPAOff. Sci. Technol. EPA/821/R-97/004. 